\title{
Mast cells in peritoneal fluid in rats with experimentally induced peritoneal adhesions
}

\author{
A. Hermanowicz ${ }^{1}$, W. Debek ${ }^{1}$, M. Oksiuta ${ }^{1}$, E. Matuszczak ${ }^{1}$, L. Chyczewski², \\ E. Dzienis-Koronkiewicz ${ }^{1}$
}

\author{
${ }^{1}$ Department of Pediatric Surgery, Medical University, Bialystok, Poland \\ ${ }^{2}$ Department of Clinical Molecular Biology, Medical University, Bialystok, Poland
}

\begin{abstract}
Mast cells (MC) produce, store and release many biologically active substances, especially inflammatory factors, chemotactic substances for neutrophiles, cytokines and prostaglandins. They play very important role in fibrinosis and they are an important factor in peritoneal adhesions formation and lysis. In this study we tried to evaluate role of mast cells in peritoneal adhesions formation. We estimated number of mast cells in peritoneal fluid in rats with experimentally developed peritoneal adhesions. The number of mast cells per ml was counted in flow cytometry in specimens of peritoneal fluid taken from operated rats. The fluid was taken in standarized conditions the same for each group at the first operation and during reoperation. Peritoneal cavity was washed with $0.9 \%$ Saline solution. MC were visualized using indirect immunohistochemical method LSAB with mouse antibody. The animals were divided into 4 groups. $1^{\text {st }}$ group was control group ( $\mathrm{n}=20$ ) on which the abdomen was opened and closed without any manipulations, and the reoperation was done after 72 hours. The other groups $(2,3,4 ; n=20$ for each group) were operated and scarification of the partial peritoneum and serosa was performed. The rats were brought back to conscious and then were reoperated respectively after 24, 72 and 168 hours after first surgery. After the laparotomy and damage of the peritoneum we observed formation of the peritoneal adhesions between intestine loops and between intestines and damaged parietal peritoneum. Also the higher number of mast cells was observed in the groups of animals with damaged peritoneum. The highest number of peritoneal adhesions was observed in the group of animals reoperated after 72 hours. After 72 and 168 hours the higher number of MC and neutrophils was observed. The difference was statistically significant. The percentage of mast cells was increasing during the experiment duration. It was different from other cells populations which decreased after 168 hours. The MC and neutrophils were cell population which changed significantly after manipulations in peritoneal cavity. It is very probable that they play an important role in peritoneal adhesions formation.
\end{abstract}

Key words: peritoneal adhesions, mast cells, peritoneum, peritoneal fluid

\section{Introduction}

Intra-abdominal adhesion formation after surgery is a significant cause of complications such as severe mechanical bowel obstruction, female infertility, or pelvic pain [1,2]. The exact cause of adhesions is still unclear even though mechanical trauma, ischemia, infection, and the presence of foreign bodies have been attributed a role [3]. Mast cells have been implicated in the aethiopathology of post-operative peritoneal adhesions as well as eosinophils, macrophages, and neutrophils by influencing some of the fibroblasts and myofibroblasts biochemical-functional properties. In

Correspondence: A. Hermanowicz, Dept. of Pediatric Surgery,

Medical University in Bialystok, Waszyngtona Str. 17,

15-274 Bialystok, Poland; e-mail: ahermanowicz@wp.pl adhesion formation process it is possible to identify a surgical trauma in conjunction with ischemia with infection that results in an acute fibroproliferative inflammatory response [4]. Post-operative adhesion may represent the final results of an exaggerated repair mechanism. Mast cell degranulation and proliferation can result even from simple handling of the bowel which was proved in a rat model [5]. Recent observations indicate that mast cells have the ability in normal and pathologic human tissues to directly produce type VIII collagen [6]. Murine mast cell lines and primary mast cells can synthesize basement membrane components such as laminin and collagen type IV [7]. Endothelial growth factor (VEGF) is central to the formation of postoperative intra-abdominal adhesions. Mast cells are responsible for VEGF release into the peritoneal cavity after operation [8].The aim of this 
study was the evaluation of the role of mast cells in peritoneal adhesions formation.

\section{Materials and methods}

Animals. Female Wistar rats in the number of seventy weighing 200-220g were housed under standard conditions, one rat in one cage, fed a pellet diet, and given tap water ad libitum before and after surgery. The rats were anesthetized with intramuscular ketamine $10 \mathrm{mg} / \mathrm{Kg}$, and the operation was carried out under sterile conditions. After the abdominal hair was shaved and the skin was sterilized with detadine, a $2-3 \mathrm{~cm}$ transverse laparotomy was performed. The small intestine was grasped with forceps and $1 \mathrm{~cm}^{2}$ of serosa of two close intestinal loops $5-10 \mathrm{~cm}$ from caecum, and colon $5 \mathrm{~cm}$ from caecum was abraded with surgical blade over each one until punctuate hemorrhage occurred. Also $1 \mathrm{~cm}^{2}$ of peritoneum next to the scarificated colon was resected. Then the small intestine was returned to the abdomen, the incision was closed in two layers with continuous 3-0 absorbable surgical suture. After 24,72 and 168 hours, groups of 10-20 rats were sacrificed for analysis of peritoneal abnormalities, and for the tests described below. Control consisted of 20 rats in which during the first laparotomy no manipulations were performed, only the peritoneal lavage with taking samples of the fluid. These rats were operated after 72 hours and once again the peritoneal lavage was performed with taking samples of the fluid.

Adhesion grading. The peritoneal cavity was opened at the different time points and the grade of adhesions was assessed according to Hulka scale system [9]:

I degree - no adhesions

II degree - avascular, thin adhesions limited to 1 area

III degree - vascular, thin adhesions in one area

IV degree - many vascular adhesions, more than one place

Immunohistochemistry. The cell counts were performed in specimens of peritoneal fluid taken from operated rats. The fluid was taken in standardized conditions the same for each group at the first operation and during reoperation. Peritoneal cavity was washed with $0.9 \%$ Saline solution. Visualization of antibodies was obtained using LSAB technique according to manufactures protocol. Mast cells were localized using monoclonal antibody - Monoclonal Mouse Anti-Human Mast Cell Tryptase, Clone AA1, Isotype IgG1 (DakoCytomation, Code M 7052). In further stages we used anti-mouse antibody combined with biotin and peroxidase (Large Volume Dako LSABR+Kit, Peroxidase, K0690). Sections were counter-stained with haematoxylin. The density of the mast cells was calculated using a light microscope Reichert-Jung with digital camera CCD Color Camera combined with IBM computer. LUCIA software was used as a morphometric tool. The MC were counted in random fields using Fuchs-Rosenthal Counter.

Ethical issues. The experimental protocol was approved by the Local Animal Experimentation Ethic Committee (no. 2004/21).

Statistical analysis. Results of adhesion scores and peritoneal lavage cells were analyzed using Microsoft Excel Statistica 5.1. Analysis of MC in different groups of animals was performed using unpaired Student's t-test. A p value of below 0.05 was considered to be statistically significant.

\section{Results}

After the laparotomy and damage of the peritoneum we observed formation of the peritoneal adhesions between intestine loops and between intestines and damaged parietal peritoneum. Also the higher number of mast cells was observed in the groups of animals with damaged peritoneum. The highest number of peritoneal adhesions was observed in the group of animals reoperated after 72 hours. After 168 hours there were less adhesions but they were more thick and vascular. Adhesions were found in scarificated intestine and peritoneum. In the control group there were no adhesions between intestine loops. In the group operated after 72 hours there were adhesions between intestine loops, scarificated peritoneum and also between the intestine and wound - which was not observed in other groups.

The number of cells per $\mathrm{ml}$ in peritoneal fluid taken from animals in each groups was different. In the control group during first laparotomy the number of cells was $10.3 \pm 0.9$ cells $\times 10^{6} / \mathrm{ml}$. In the same group in the second laparotomy performed after 72 hours there were $11.2 \pm 2.5 \times 10^{6} / \mathrm{ml}$ cells (statistically insignificant). In the group in which laparotomy was performed 24 hours after surgery and scarification, the number of cells in the peritoneal fluid was $21.3 \pm 3.5$ $\mathrm{x} 10^{6} / \mathrm{ml}(\mathrm{p}<0.001)$. In the group operated 72 hours after laparotomy and scarification the number of cells in peritoneal fluid was $20.1 \pm 3.0 \times 10^{6} / \mathrm{ml}(\mathrm{p}<0.001)$. In the group operated 168 hours after laparotomy and scarification the number of cells in the peritoneal fluid was $12.7 \pm 1.7$ (statistically not significant in the comparison with the first group).

After 24 and 72 hours the higher number of cells was observed. The difference was statistically significant. The percentage of mast cells was increasing during the experiment duration.

In the control group the percentage of $\mathrm{MC}$ in the peritoneal fluid taken after lavage was $5.0 \pm 1.7$. In samples taken during laparotomy after 72 hours the

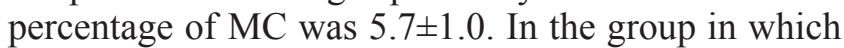
the samples were taken during laparotomy performed 24 hours after surgery and scarification the percentage of $\mathrm{MC}$ was $6.5 \pm 1.9$. In the group in which samples were taken during laparotomy 72 hours after surgery and scarification the percentage of $\mathrm{MC}$ in the peritoneal fluid was $9.9 \pm 3.0(p<0.05)$. In the group operated 168 hours after first laparotomy and scarification the percentage of $\mathrm{MC}$ in the peritoneal fluid was $11.5 \pm 2.2(p<0.001)$. MC in all groups possessed similar morphometric parameters.

\section{Discussion}

The peritoneum is in constant contact with the peritoneal fluid. It is likely that the activity of cellular mediators in the peritoneal fluid plays an active role in peritoneal healing. These cellular mediators are produced by the cellular components of the peritoneal 


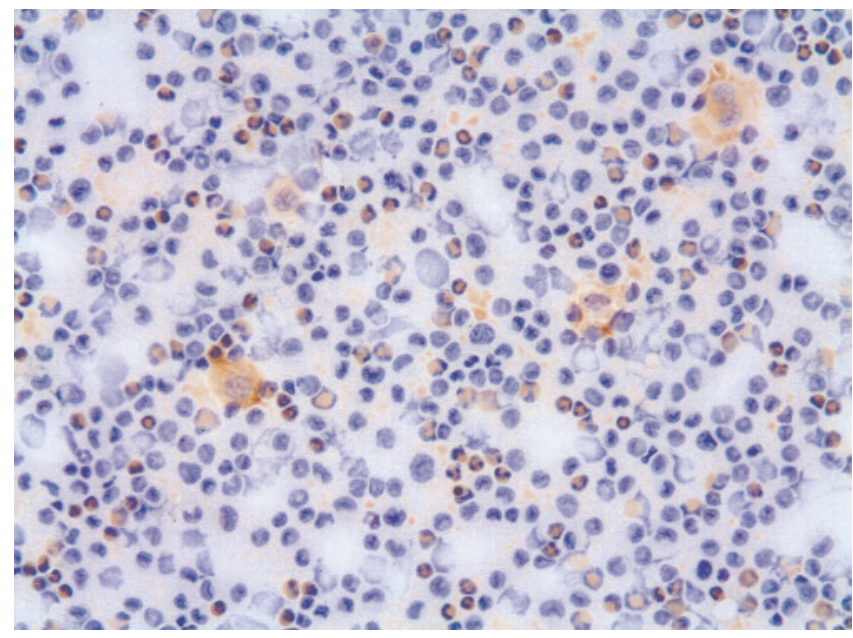

Fig. 1. Mast cells $(\mathrm{MC})$ in peritoneal fliud in rat reoperated after 24 hours (group 2) (original magnification $\times 200$ ).

fluid such as the mast cells, the macrophages, the neutrophils and the eosinophils $[10,11]$. Surgical trauma triggers inflammation process which causes an increase in vascular permeability and release of fibrinrich exudates [12]. If the fibrin is not lysed through the plasminogen-plasmin cascade, adhesions may form through collagen deposition on a framework of proteoglycan and fibronectin [13]. Plasmin can be produced by macrophages or by mesothelial cells lining the peritoneal cavity [10]. The main role of plasmin is to degrade fibrin. To counteract this process, plasminogen activator inhibitor-1 (PAI-1) and PAI-2, inhibit both tissue plasminogen activator (tPA) and urokinaselike plasminogen activator (uPA) to different degrees. In the pathological process of adhesion formation, the fibrynolytic process is altered, allowing the formation and persistence of adhesions [14]. There is alteration in peritoneal fluid cytokine profile in the presence of adhesions. In acute inflammation, the peritoneal fluid shows increased concentrations of the pro-inflammatory cytokines IL-1, IL-6, IL-8 and TNF-alpha [15]. Acute inflammation in the peritoneum is followed by a large influx of cells, predominately macrophages, by chemotactic mechanisms. IL-1 and TNF-alpha are both pro-inflammatory cytokines important in the early phase of wound healing and are produced by activated macrophages in the peritoneal fluid $[16,17]$. It is known that TNF-alpha, IL-1 and IL-6 interact with the fibrynolytic system. Plasmin has been shown to mobilize and release TNF-alpha, Il-1 and IL-6 [18]. TNF-alpha and Il-1beta can in turn down-regulate tPA expression both at the protein and the mRNA level, thus helping to regulate the inflammatory process and, possibly the extent and severity of adhesion formation [19]. In this study peritoneal adhesions in rats were induced by scarification of the partial peritoneum and serosa in a trial to mimic surgical intervention -

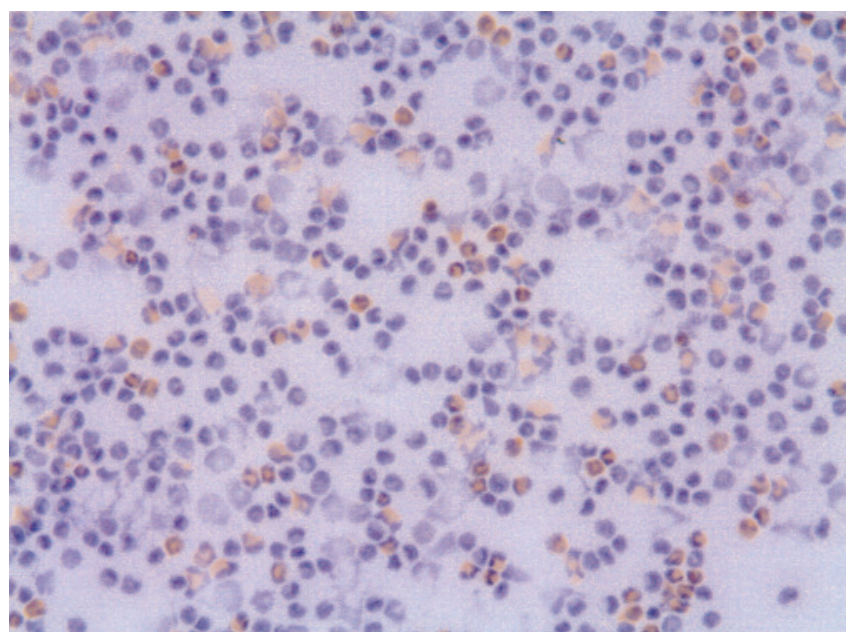

Fig. 2. A great number of $\mathrm{MC}$ and neutrophils in peritoneal fluid 72 hours after operation (group 3) (original magnification $\times 200$ ).

laparotomy. The highest number of peritoneal adhesions was observed in the group of animals reoperated after 72 hours. The process of adhesion formation takes place in the peritoneum, also mast cells in the peritoneal lavage were evaluated. The increase in the number of mast cells during the first few days postsurgery is a consequence of their proliferation, maturation and migration. Mast cells (MC) present in the peritoneal adhesions could have migrated from the intestinal wall. MC are the critical effector cells of allergic inflammation, and have a crucial role in tissue reparative reactions and natural immunity $[20,21]$, and are normal resident cells of the gastrointestinal tract, where they represent a host defense system [20]. MC are capable of reacting to a variety of physical, biologic and chemical stimuli and are degranulated when an inflammatory process takes place $[20,22]$. MC can induce fibroplasia by the release of mediators such as histamine [23,24], tryptase [25-27], TGF-beta or TNFalpha [13]. In this study we have shown that post-operative peritoneal adhesion formation in a rat model correlates with mast cell changes in number and activation state. MC in all specimens possessed similar morphometric parameters - irregular shape and centrally located nucleus. Activation of $\mathrm{MC}$ and their degranulation cause change in cell area, perimeter and decrease in shape factor [28]. The identification of types of MC - mucosal MC from the intestinal wall and connective tissue $\mathrm{MC}$ recruited from the bone marrow will be the aim of our next study.

The results of our study are concomitant with the results of other authors, but there are no publications assessing percentage of MC in the samples of peritoneal fluid taken in different time after laparotomy and scarification of the peritoneum. The biggest percentage of MC was observed on the seventh day after the laparotomy. These data indirectly suggests that 
mast cells influence peritoneal adhesion formation and also take part in adhesion remodeling, because the highest number of peritoneal adhesions was found after 72 from the first surgery. After 168 hours from the first laparotomy and scarification of intestine and peritoneum, adhesions were less severe.

There is no ideal method of preventing adhesion formation. In terms of surgical technique, gentle tissue handling, the no-touch technique, meticulous hemostasis, avoidance of powdered gloves and prevention of thermal injury have all been described as means of adhesion prevention [24]. A better understanding of the pathogenesis of adhesion formation at the cellular and molecular level would help to develop more effective treatment strategies.

\section{Conclusions}

The present work indirectly demonstrates the role of mast cells in the formation and establishment of peritoneal adhesions in a rat model. After scarification of peritoneum and serosa in rats, the process of adhesion formation was observed, adhesions were most prominent in the third day after the laparotomy. The laparotomy and scarification of peritoneum and serosa mobilized mast cells from the peritoneal fluid, and the biggest number of MC was observed on the seventh day after the laparotomy. These data suggests that mast cells influence peritoneal adhesion formation and also take part in adhesion remodeling. These results indicate that the rat model is a valuable tool for studying the contribution of mast cells in traumatic inflammation.

\section{References}

[1] Scott-Coombes DM, Vipond MN, hompson JN: General surgeons' attitudes to the treatment and prevention of abdominal adhesions. Ann R Coll Surg Engl. 1993;75:123-128.

[ 2] Xu X, Rivkind A, Pappo O, Pikarsky A, Levi-Schaffer F: Role of mast cells and myofibroblasts in human peritoneal adhesion formation. Ann Surg. 2002;236(50:593-601.

[3] Thomson J. Pathogenesis and prevention of adhesion formation. Dig Surg. 1998;15:153-157.

[4] Milligan DW, Rafter AT: Observations on the pathogenesis of peritoneal adhesions: A light and electron microscopical study. BJ Surg. 1974;61:274.

[5] Collins S. et al. The immunomodulation of gut motility: factors that determine the proliferation of mast cells in the sensitized gut. Gastroenterology. 1988;94:A74.

[6] Ruger B, Dunbar PR, Hasan Q et al. Human mast cels produce type VIII collagen in vivo. Int $J$ Exp Pathol. 1994;75:397-404.

[ 7] Tompson HL, Burbelo PD, Gabriel G, et al. Murine mast cells synthesize basement membrane components. A potential role of early fibrosis. J Clin Invest. 1991;87:619-623.

[8] Cahill RA, Wang JH, Soohkai S, Redmond HP. Mast cells facilitate local VEGF release as an early event in the pathogenesis of postoperative peritoneal adhesions. Surg. 2006;140:108-112.
[ 9] Hulka J, Omran K and Berger G., Classification of adnexal adhesions: a proposal and evaluation of its prognostic value. Fertil Steril. 1978;30:661-665.

[10] Cheong YC, Laird SM, Li TC, Shelton JB, Ledger WL, Cooke ID. Peritoneal healing and adhesion formation/reformation. Hum Reprod Update. 2001;7:556-566.

[11] Zareie M, Fabbrini P, Hekking LHP, Keuning ED, Wee PM, Beelen R, Born J. Novel role for mast cells in omental tissue remodeling and cell recruitment in experimental peritoneal dialysis. J Am Soc Nephrol. 2006;17:3447-3457.

[12] Harris ES, Morgan RF, Rodeheaver GT. Analysis of the kinetics of peritoneal adhesion formation in the rat and evaluation of potential antiadhesive agents. Surg. 1995;117:66-669.

[13] Xu X, Pappo O, Garbuzenko E, Bischoff SC, Rivkind A, Levi-Schaffer F. Mast cell dynamics and involvement in the development of peritoneal adhesions in the rat. Live Sci. 2002;70:951-967.

[14] DiZerega GS, Campeau JD. Peritoneal repair and post-surgical adhesion formation. Hum Rep Update. 2001;7:547-555.

[15] Brauner A, Hylander B, Wretlind B. TNF-alpha, IL-1beta and IL-1 receptor antagonist in dialysate and serum from patients on CAPD. Am J Kidney Dis. 1996;27:402-408.

[16] Lowry S. Cytokines mediators of immunity and inflammation. Arch Surg. 1993;128:1235-1241.

[17] Mori H, Sawairi M, Nakagawa M et al. Peritoneal fluid IL-1 beta and TNF in patients with benign gynaecological disease. Am J Reprod Immun. 1991;26:62-67.

[18] Ivarsson M, Holmdahl L, Falk P et al. characterization and fibrynolytic properties of mesothelial cells isolated from peritoneal lavage. Scand J Clin Lab Invest. 1998;58:195-203.

[19] Tietze L, Elbreht A, Schauerte C et al. Modulation of pro and antifibrinolytic properties of human peritoneal mesothelial cells by transforming growth factor beta1, tumor necrosis factor alpha and interleukin 1beta. Thromb Haemost. 1998;79:362-370.

[20] Metcalfe D, Baram D and Mekori Y. Mast cells. Physiol Rev. 1997;77:1033-1079.

[21] Wedemeyer J, Tsai M, Galli SJ. Roles of mast cells and basophils in innate and acquired immunity. Curr Opin Immunol. 2000;12:624-631.

[22] Levi-Schaffer F. Mast cell/fibroblast interactions in health and disease. Chem Immunol. 1995;61:161-185.

[23] Kupietzky A, Levi-Schaffer F. The role of mast cell-derived histamine in the closure of an in vitro wound. Infl Res. 1996;45:176-180.

[24] Norrby K. Evidence of mast cell histamine being mitogenic in intact tissue. Agents Actions. 1985;16:287-290.

[25] Gruber BL, Kew RR, Jelaska A, Marchese MJ, Garlick J, Schwartz LB, Korn JH. Human mast cells activate fibroblasts. Tryptase is a fibrogenic factor stimulating collagen messenger ribonucleic acid synthesis and fibroblast chemotaxis. $J$ Immunol. 1997;158:2310-2317.

[26] Hartmann T, Ruoss ST, Raymond WW, Seuwen K, Caughey GH. Human tryptase as a potent, cell-specific mitogeFce R1. Role for mast cell-derived Transforming Growth Factor beta and Tumor Necrosis Factor alpha. $J$ Exp Med. 1994;180:2027-2037.

[27] Ruoss S, Hartmann T and Caughey H. Mast cell tryptase is a mitogen for cultured fibroblasts. J Clin Invest. 1991;88:493499.

[28] Levi-Schaffer F, Slovik D, Armetti L, Pickholtz D, Touitou E. Activation and inhibition of mast cells degranulation affect their morphometric parameters. Life Sci. 2000;66:283-290.

Submitted: 30 June, 2009 Accepted after reviews: 24 Ocober, 2009 